\title{
Intraoperative radiotherapy to treat newly diagnosed solitary brain metastasis: initial experience and long-term outcomes
}

\author{
Robert J. Weil, MD, ${ }^{1,2,4}$ Gaurav G. Mavinkurve, MD, ${ }^{2}$ Samuel T. Chao, MD, ${ }^{1,3,4}$ \\ Michael A. Vogelbaum, MD, PhD, ${ }^{1,2,4}$ John H. Suh, MD,,3,4 Matthew Kolar, MS, ${ }^{3}$ \\ and Steven A. Toms, MD, MPH ${ }^{5}$ \\ ${ }^{1}$ The Rose Ella Burkhardt Brain Tumor and Neuro-Oncology Center, ${ }^{2}$ Department of Neurosurgery, Neurological Institute, \\ ${ }^{3}$ Department of Radiation Oncology, and ${ }^{4}$ Taussig Cancer Institute, Cleveland Clinic, Cleveland, Ohio; and ${ }^{5}$ Department of \\ Neurosurgery, Neuroscience Institute, Geisinger Health System, Danville, Pennsylvania
}

\begin{abstract}
OBJECT The authors assessed the feasibility of intraoperative radiotherapy (IORT) using a portable radiation source to treat newly diagnosed, surgically resected, solitary brain metastasis $(\mathrm{BrM})$.

METHODS In a nonrandomized prospective study, 23 patients with histologically confirmed BrM were treated with an Intrabeam device that delivered $14 \mathrm{~Gy}$ to a 2 -mm depth to the resection cavity during surgery.

RESULTS In a 5-year minimum follow-up period, progression-free survival from the time of surgery with simultaneous IORT averaged ( \pm SD) $22 \pm 33$ months (range 1-96 months), with survival from the time of BrM treatment with surgery $+\mid \mathrm{ORT}$ of $30 \pm 32$ months (range 1-96 months) and overall survival from the time of first cancer diagnosis of 71 \pm 64 months (range 4-197 months). For the Graded Prognostic Assessment (GPA), patients with a score of 1.5-2.0 ( $n=$ 12) had an average posttreatment survival of $21 \pm 26$ months (range 1-96 months), those with a score of 2.5-3.0 $(n=7)$ had an average posttreatment survival of $52 \pm 40$ months (range 5-94 months), and those with a score of 3.5-4.0 ( $\mathrm{n}=$ 4) had an average posttreatment survival of $17 \pm 12$ months (range 4-28 months). A BrM at the treatment site recurred in 7 patients $9 \pm 6$ months posttreatment, and 5 patients had new but distant BrM $17 \pm 3$ months after surgery+IORT. Six patients later received whole-brain radiation therapy, 7 patients received radiosurgery, and 2 patients received both treatments. The median Karnofsky Performance Scale scores before and 1 and 3 months after surgery were 80, 90, and 90 , respectively; at the time of this writing, 3 patients remain alive with a CNS progression-free survival of $>90$ months without additional BrM treatment.
\end{abstract}

CONCLUSIONS The results of this study demonstrate the feasibility of resection combined with IORT at a dose of 14 Gy to a 2-mm peripheral margin to treat a solitary BrM. Local control, distant control, and long-term survival were comparable to those of other commonly used modalities. Surgery combined with IORT seems to be a potential adjunct to patient treatment for CNS involvement by systemic cancer.

Clinical trial registration no.: NCT00107367 (clinicaltrials.gov)

http://thejns.org/doi/abs/10.3171/2014.11.JNS1449

KEY WORDS stereotactic radiosurgery; linear accelerator; dosimetry

\footnotetext{
ABBREVIATIONS BrM = brain metastasis; GPA = Graded Prognostic Assessment; IORT = intraoperative radiotherapy; $K P S=$ Karnofsky Performance Scale; $L M D=$ leptomeningeal (metastatic) disease; NSCLCa = non-small cell lung cancer; RPA = recursive partitioning analysis; SRS = stereotactic radiosurgery; WBRT = whole-brain radiation therapy; XRS = radiation source.

SUBMITTED January 30, 2014. ACCEPTED November 13, 2014.

INCLUDE WHEN CITING Published online January 23, 2015; DOI: 10.3171/2014.11.JNS1449.

DISCLOSURE The authors report no conflict of interest concerning the materials or methods used in this study or the findings specified in this paper. The following grants funded this study: grant W81XWH-062-0033 from the United States Department of Defense Breast Cancer Research Program (to Dr. Weil) and grants from the Cleveland Clinic, Neurosurgical Oncology (Melvin Burkhardt, chair; Karen Colina Wilson, research endowment), and the Brain Tumor and Neuro-oncology Center, Cleveland Clinic Foundation (to Dr. Weil).
} 
$\mathrm{B}$ RAIN metastasis (BrM) is a common manifestation of systemic cancer and occurs in at least an estimated 100,000 patients yearly in the United States. ${ }^{2,432,41}$ Whole-brain radiation therapy (WBRT), alone or in combination with excision, has been used for traditional and palliative therapy for nearly all patients with BrM. 4,15,19,20,22,23,30-32,41,43,44 Most recently, stereotactic radiosurgery (SRS) has been added to the palliative armamentarium. ${ }^{20,37,40}$ Most chemotherapeutic agents are impotent in the treatment of BrMs because of the relative impenetrability of the blood-brain and blood-tumor barriers. ${ }^{12,13,22,26}$

Historically, average survival times for patients with BrM have been 3-12 months, with patient survival primarily determined by the status of systemic (non-CNS) disease. ${ }^{13,26,32,37}$ Given these prospects, palliative measures such as WBRT, with diminished concern for potential longterm complications on the CNS, have been used in many patients. More recently, therapies that treat well-selected patient subgroups with metastatic cancer more effectively, such as HER-2 inhibition in women with HER-2-positive breast cancer, blockade of cytotoxic T-lymphocyte-associated antigen 4 (CTLA-4) in melanoma, and the inhibition of angiogenesis in renal cell cancer, have been developed and enhance long-term survival for some patients. ${ }^{13}$ Thus, preservation of CNS function by treating solitary or oligometastases of the brain locally rather than globally has become a potential goal. $5,26,38,39,46$ To assess the utility of local definitive treatment, we performed a feasibility study of single-dose, targeted, intraoperative radiotherapy (IORT) at the time of resection of a solitary BrM as the primary treatment for metastatic cancer and report here our long-term outcomes.

\section{Methods \\ Device Description}

The Intrabeam (Carl Zeiss) is a mobile IORT system consisting of a miniature low-energy radiation source (XRS) mounted on a balanced floor stand with 6 degrees of freedom. The XRS consists of a chromium nitridecoated vacuum probe that is $10 \mathrm{~cm}$ long and $3.2 \mathrm{~mm}$ in diameter. Within this evacuated probe, electrons are accelerated to strike a gold target, resulting in the production of an isotropic dose distribution around the tip of the probe. A set of interchangeable plastic spherical applicators (with diameters ranging from 1.5 to $5 \mathrm{~cm}$ ) is provided for attachment to the probe. The XRS is powered and controlled by a portable electronic console. The device produces "soft" low-energy radiation $(30-50 \mathrm{kV})$ attenuated rapidly within tissue with a dose-decline rate inversely proportional to the third power of the distance, thereby reducing damage to the surrounding normal brain parenchyma. Background exposure is minimal; shielding of the operating room is not required.

\section{Patients and Surgery}

From October 2004 to August 2007, 23 patients with a single newly diagnosed intracranial metastasis at the Cleveland Clinic were offered participation in this prospective study, which was approved by the Cleveland Clinic Institutional Review Board; informed consent was given by each patient. The patients consented to undergo
IORT only if the frozen section confirmed metastatic carcinoma. All 23 enrolled patients were confirmed to have $\mathrm{BrM}$ and met the eligibility criteria before IORT began. The study was registered at ClinicalTrials.gov (registration no. NCT00107367).

The study was open to adult patients with a surgically accessible, newly diagnosed, supratentorial, single cerebral BrM, confirmed on MRI with histological evidence of metastatic carcinoma on frozen-section analysis of tissue resected at the time of surgery+IORT. In addition, case selection was limited to patients with an anticipated life expectancy of at least 3 months. Patients with primary lymphoma, germ cell carcinoma, or small cell lung cancer were excluded, but those with radioresistant histologies such as melanoma, renal cell carcinoma, or sarcoma were not excluded. Patients were excluded if they were receiving or had received previous brain radiotherapy of any kind or had other therapy directed at the solitary metastasis (e.g., local chemotherapeutic agents such as polifeprosan 20 with a carmustine implant or directed only at the BrM [such as temozolomide]). Pregnant women were excluded.

\section{Intraoperative Radiotherapy}

Gross-total resection of the single metastasis was performed using surgical navigation and intraoperative ultrasound guidance. Appropriate preoperative antibiotics and steroids were administered. After the tumor was resected, metastasis was confirmed by frozen section, and hemostasis was achieved, we measured the tumor cavity with an appropriately sized, sterilized applicator selected to fit the tumor cavity by measuring the tumor cavity's cross-sectional diameter with a ruler. A radiation physicist performed quality assurance of the Intrabeam system before the initiation of treatment. The Intrabeam device and arm were draped with a sterile clear-plastic cover and the selected sterile applicator was attached to the probe. The applicator was positioned within the tumor cavity so that the spherical applicator was in direct contact with the tumor bed. After correct positioning of the applicator, a standard dose of 14 Gy was delivered to the resection cavity to a depth of $2 \mathrm{~mm}$, per the treatment protocol. This dose was chosen on the basis of previous experience reported in the literature and on experience with SRS dosing at our institution. ${ }^{1,8,10,11,14,16,18,28,34}$ All nonessential personnel left the operating room. The surgeon and anesthetist remained behind a leaded-glass shield while the treatment was delivered. Portable radiation shields minimized radiation exposure. After delivery of the prescribed dose, the applicator was removed, and the patient's craniotomy was completed. WBRT or other postoperative adjuvant therapies were not offered to patients after Intrabeam IORT unless radiographic or clinical evidence of tumor progression was identified.

\section{Assessment of Complications and Treatment Toxicities}

All patients underwent clinical evaluation, Karnofsky Performance Scale (KPS) assessment, Folstein testing, and MRI preoperatively (Tables 1 and 2). ${ }^{9,36}$ Postoperatively, MRI was performed approximately 24 hours after surgery, and postoperative care was unchanged. Follow-up 
TABLE 1. Preoperative and operative characteristics

\begin{tabular}{|c|c|c|c|c|c|c|c|c|}
\hline Patient No. & $\begin{array}{c}\text { Age (yrs), } \\
\text { Sex }\end{array}$ & $\begin{array}{l}\text { Location, } \\
\text { Side }\end{array}$ & $\begin{array}{l}\text { Interval to } \\
\text { Met (mos) }\end{array}$ & Primary Cancer Type* & $\begin{array}{l}\text { Lesion Size } \\
(\mathrm{cm}) / \mathrm{Vol}\left(\mathrm{cm}^{3}\right)\end{array}$ & GPA Score & LOS (days) & $\begin{array}{l}\text { No. of Days } \\
\text { on Dex }\end{array}$ \\
\hline 1 & $62, \mathrm{M}$ & $\mathrm{T}, \mathrm{rt}$ & 16 & Renal & $3.6 / 20.8$ & 1.5 & 10 & 14 \\
\hline 2 & $69, \mathrm{~F}$ & Fr, It & 17 & Leiomyosarcoma & $3.1 / 14.4$ & 2.5 & 3 & 14 \\
\hline 3 & $53, \mathrm{M}$ & P, It & 28 & Melanoma & $3.0 / 9.3$ & 2 & 2 & 14 \\
\hline 4 & $66, M$ & $\mathrm{~T}, \mathrm{rt}$ & 4 & NSCLCa & $3.1 / 13.5$ & 3 & 3 & 21 \\
\hline 5 & $61, \mathrm{~F}$ & $P$, It & 109 & Renal (1); breast (2) & $2.5 / 6.3$ & 2.5 & 2 & 10 \\
\hline 6 & $55, \mathrm{~F}$ & $\mathrm{P}, \mathrm{rt}$ & 141 & Endometrial & $2.0 / 3.2$ & 3.5 & 2 & 14 \\
\hline 7 & $65, F$ & $\mathrm{Fr}, \mathrm{rt}$ & 26 & NSCLCa & $4.0 / 21.8$ & 1.5 & 2 & 14 \\
\hline 8 & $52, \mathrm{M}$ & $0, \mathrm{rt}$ & 21 & Prostate & $3.4 / 15.3$ & 2 & 2 & 10 \\
\hline 9 & $42, F$ & 0, It & 77 & Breast & $6.5 / 72.2$ & 3 & 3 & 10 \\
\hline 10 & $40, M$ & 0, It & 16 & Renal & $2.0,4.0$ & 4 & 2 & 14 \\
\hline 11 & $52, \mathrm{M}$ & $\mathrm{P}, \mathrm{rt}$ & 19 & NSCLCa & $4.4 / 37.0$ & 3 & 2 & 14 \\
\hline 12 & $59, \mathrm{~F}$ & Fr, It & 132 & Breast (1); NSCLCa (2) & $2.0 / 3.8$ & 2 & 2 & 10 \\
\hline 13 & $72, \mathrm{M}$ & $\mathrm{T}, \mathrm{It}$ & 0 & NSCLCa & $2.0 / 3.6$ & 1.5 & 3 & 10 \\
\hline 14 & $63, \mathrm{M}$ & $\mathrm{P}, \mathrm{rt}$ & 6 & NSCLCa & $1.5 / 1.7$ & 1.5 & 9 & 14 \\
\hline 15 & $69, \mathrm{~F}$ & 0, It & 196 & Breast (1); NSCLCa (2) & $4.3 / 39.5$ & 2.5 & 2 & 14 \\
\hline 16 & $82, \mathrm{~F}$ & $\mathrm{~T}$, It & 88 & NSCLCa & $4.0 / 20.3$ & 1.5 & 5 & 14 \\
\hline 17 & $53, \mathrm{~F}$ & $\mathrm{Fr}, \mathrm{rt}$ & 25 & Breast & $2.3 / 5.1$ & 3.5 & 2 & 10 \\
\hline 18 & $60, M$ & $\mathrm{~T}$, It & 0 & NSCLCa & $2.4 / 5.8$ & 1.5 & 3 & 14 \\
\hline 19 & $61, \mathrm{M}$ & $\mathrm{Fr}, \mathrm{rt}$ & 14 & Transitional bladder & $2.8 / 8.1$ & 3 & 2 & 10 \\
\hline 20 & $74, \mathrm{M}$ & $\mathrm{P}, \mathrm{rt}$ & 0 & Esophageal & $1.9 / 2.3$ & 1.5 & 5 & 14 \\
\hline 21 & $51, \mathrm{~F}$ & $\mathrm{Fr}, \mathrm{rt}$ & 20 & Colorectal & $2.6 / 8.8$ & 3.5 & 3 & 21 \\
\hline 22 & $66, \mathrm{M}$ & $\mathrm{P}$, It & 0 & NSCLCa & $2.5 / 6.6$ & 1.5 & 2 & 7 \\
\hline 23 & $81, \mathrm{M}$ & $\mathrm{Fr}, \mathrm{rt}$ & 8 & Bladder & $2.7 / 9.5$ & 1.5 & 5 & 14 \\
\hline Mean & 61.2 & & 41.9 & & $3.0 / 14.5$ & & 3.3 & 13.1 \\
\hline SD & 10.8 & & 54.5 & & $1.2 / 16.2$ & & 2.2 & 3.3 \\
\hline Median & 61 & & 19 & & $2.7 / 8.8$ & & 2 & 14 \\
\hline Mode & 69 & & 0 & & 2.0/NA & & 2 & 14 \\
\hline
\end{tabular}

Dex = dexamethasone; $\mathrm{Fr}=$ frontal; GPA-DS = disease-specific GPA (where applicable); LOS = length of stay; Met $=$ metastasis; $\mathrm{NA}=$ not applicable; $\mathrm{O}=$ occipital; $\mathrm{P}=$ parietal; $\mathrm{T}=$ temporal.

* Numbers in parentheses indicate the order in which cancers were diagnosed for patients with more than one type.

exams were conducted at 1 month, 3 months, and every 3 months thereafter to 5 years. Patient data, including those from physical and neurological examinations, steroid medication dose, KPS score, Folstein assessments, and adverse-event information, were collected at each follow-up visit. MRI was performed at each visit. These scans were compared with previous images to evaluate local control (defined as the absence of tumor recurrence within $2.5 \mathrm{~cm}$ from the tumor cavity on contrast-enhanced MRI), distant tumor recurrence, and radiation necrosis. Neuroimaging was performed if a patient developed symptoms or signs suggesting the recurrence of BrM. If recurrence was suspected, a reoperation or a biopsy was performed. If recurrence was confirmed, additional therapies were given, as clinically indicated (Table 2).

\section{Results}

Twenty-three patients underwent resection of BrM and contemporaneous targeted IORT using the Intrabeam. Patient characteristics and outcomes are listed in Tables 1 and 2 . Thirteen patients $(56.5 \%)$ were men. The patients underwent resection without incident, except for 2 patients who experienced perioperative lower-extremity deep venous thrombosis (within 30 days of surgery).

The average $( \pm$ SD) largest dimension of the excised $\mathrm{BrM}$ was $3.0 \pm 1.2 \mathrm{~cm}$ (range $15-65 \mathrm{~cm}$ ), and the average lesion volume was $14.5 \pm 16.2 \mathrm{~cm}^{3}$ (range $1.7-72.3 \mathrm{~cm}^{3}$ ). Of the 23 patients, 8 were grouped into recursive partitioning analysis (RPA) Class I and 15 were grouped into RPA Class II; 12 had a Graded Prognostic Assessment (GPA) score of 1.5-2.0, 7 had a GPA score of 2.5-3.0, and 4 had a GPA score of 3.5-4.0.

At surgery, IORT was performed successfully and safely in all 23 patients. Different size applicators (range $1.5-4.0 \mathrm{~cm}$ ) were chosen on the basis of the size of the resection cavity to ensure that the applicator was in direct contact with the entire resection cavity. A delivered dose of $14 \mathrm{~Gy}$ to a calculated depth of $2 \mathrm{~mm}$ for an average of $15.9 \pm 4.8$ minutes (range $8.4-25$ minutes) was used in all cases. Including the day of surgery, the average length of hospital stay was $3.3 \pm 2.2$ days (range 2-10 days; median 3 days). Dexamethasone, which was given to each patient for a symptomatic BrM with surrounding cerebral edema, 
TABLE 2. Patient characteristics and outcomes*

\begin{tabular}{|c|c|c|c|c|c|c|c|c|}
\hline \multirow{2}{*}{$\begin{array}{l}\text { Patient } \\
\text { No. }\end{array}$} & \multicolumn{3}{|c|}{ KPS Score } & \multirow{2}{*}{$\begin{array}{l}\text { PFS } \\
\text { (mos) }\end{array}$} & \multirow{2}{*}{$\begin{array}{c}\text { OS } \\
(\operatorname{mos})\end{array}$} & \multirow{2}{*}{$\begin{array}{l}\text { CNS Survival } \\
\qquad \text { (mos) } \ddagger\end{array}$} & \multirow{2}{*}{$\begin{array}{l}\text { Cause of } \\
\text { Death }\end{array}$} & \multirow[b]{2}{*}{ Comments } \\
\hline & Preop & $1 \mathrm{Mo}^{*}$ & 3 Mos† & & & & & \\
\hline 1 & 70 & 90 & 90 & 11 & 49 & 33 & S, CNS & $\begin{array}{l}\text { Recurrence at } 11 \text { mos at I/B site; re-resection, WBRT ( } 30 \text { Gy/10 } \\
\text { fractions); re-recurrence } 6 \text { mos later treated w/ SRS ( } 15 \text { Gy to } 51 \% \\
\text { IDL); craniotomy for radionecrosis at site } 12 \text { mos later; } 4 \text { mos later, } \\
\text { disseminated systemic \& diffuse CNS \& spine mets }\end{array}$ \\
\hline 2 & 70 & 90 & 90 & 96 & 110 & 96 & NA & Alive \& well; no evidence of CNS disease \\
\hline 3 & 70 & 100 & 100 & 94 & 122 & 94 & NA & $\begin{array}{l}\text { Hemorrhagic lesion at I/B site at } 18 \text { mos, repeat craniotomy; blood clot } \\
\text { identified; no tumor \& no evidence of recurrence; alive \& well, no } \\
\text { evidence of CNS disease }\end{array}$ \\
\hline 4 & 90 & 90 & 100 & 4 & 36 & 21 & S, CNS & $\begin{array}{l}\text { Recurrence at I/B site at } 4 \text { mos, treated w/ SRS; re-resection } 8 \text { mos } \\
\text { later for recurrence; re-resection } 7 \text { mos later for recurrence \& ra- } \\
\text { dionecrosis; rapid progression of systemic disease, CNS tumor, \& } \\
\text { pneumonia } 2 \text { mos later }\end{array}$ \\
\hline 5 & 80 & 90 & 90 & 90 & 189 & 90 & NA & Alive, progressive systemic disease, under treatment; no CNS disease \\
\hline 6 & 90 & 100 & 100 & 18 & 168 & 27 & CNS & $\begin{array}{l}\text { Progression at I/B site at } 18 \text { mos, re-resection, then WBRT; recurrence } \\
6 \text { mos later w/o response; death from CNS disease } 3 \text { mos later }\end{array}$ \\
\hline 7 & 70 & 90 & 90 & 6 & 35 & 10 & CNS, S & $\begin{array}{l}\text { New lesion It frontal lobe \& dura, } 6 \text { mos after l/B, treated w/ SRS (24 } \\
\text { Gy to } 70 \% \text { IDL); } 4 \text { mos later w/ LMD along the left cranium, w/ } \\
\text { concurrent \& widespread systemic dissemination }\end{array}$ \\
\hline 8 & 70 & 80 & 100 & 9 & 35 & 14 & S & $\begin{array}{l}\text { Multiple new CNS lesions (not at I/B site) at } 9 \text { mos, treated w/ WBRT } \\
\text { (3000 Gy/10 fractions); no evidence of CNS recurrence at death }\end{array}$ \\
\hline 9 & 90 & 100 & 100 & 8 & 132 & 55 & CNS, S & $\begin{array}{l}\text { SRS for anterior recurrence ( } 15 \text { Gy to } 50 \% \text { IDL) } 8 \text { mos after l/B; } 2 \text { nd } \\
\text { recurrence, posteriorly, treated w/ SRS, } 15 \text { Gy to } 51 \% \text { IDL, } 10 \text { mos } \\
\text { later; } 31 \text { mos later, SRS for } 4 \text { new brain lesions; systemic \& CNS } \\
\text { progression leading to death } 6 \text { mos later }\end{array}$ \\
\hline 10 & 90 & 100 & 100 & 10 & 26 & 10 & S & Disseminated systemic disease; no CNS recurrence \\
\hline 11 & 80 & 90 & 90 & 84 & 103 & 84 & NA & Alive \& well; no CNS recurrence \\
\hline 12 & 80 & 90 & 90 & 19 & 165 & 33 & CNS & $\begin{array}{l}\text { LMD recurrence at I/B site, treated w/ WBRT at } 16 \text { mos ( } 30 \mathrm{~Gy} / 10 \\
\text { fractions); recurrent LMD } 11 \text { mos later, treated w/ IMRT ( } 20 \mathrm{~Gy} \text { in } 5 \\
\text { fractions) w/ progression at } 6 \text { mos (death) }\end{array}$ \\
\hline 13 & 80 & 90 & 90 & 9 & 21 & 21 & S & No evidence of CNS disease at time of death \\
\hline 14 & 80 & 90 & 90 & 1 & 7 & 1 & $S$ & $\begin{array}{l}\text { Systemic progression of disease, patient declined further therapy; no } \\
\text { CNS disease }\end{array}$ \\
\hline 15 & 80 & 90 & 80 & 5 & 197 & 5 & $S$ & No evidence of CNS disease \\
\hline 16 & 70 & 80 & 90 & 1 & 89 & 1 & S & Died of acute pulmonary saddle embolus; no evidence of CNS disease \\
\hline 17 & 100 & 100 & NA & 3 & 53 & 28 & S & $\begin{array}{l}\text { At } 3 \text { mos, } 1 \text { new lesion \& new enhancement of dural LMD at I/B site, } \\
\text { both treated w/ SRS ( } 18 \text { Gy to } 51 \% \text { IDL for I/B site); cause of death } \\
\text { at } 28 \text { mos was systemic progression; no evidence of CNS disease }\end{array}$ \\
\hline 18 & 80 & 90 & 100 & 9 & 18 & 18 & S & $\begin{array}{l}\text { Multiple new distant brain lesions at } 9 \text { mos (none at l/B site), treated w/ } \\
\text { WBRT ( } 3000 \text { Gy/10 fractions); SRS } 3 \text { mos later for residual lesion } \\
\text { from SRS session; died of systemic progression } 6 \text { mos later; no } \\
\text { CNS disease }\end{array}$ \\
\hline 19 & 90 & 90 & 90 & 3 & 24 & 10 & CNS & $\begin{array}{l}\text { Recurrence of lesion at } 3 \text { mos, treated w/ SRS ( } 16 \text { Gy to } 53 \% \text { IDL); re- } \\
\text { resection for recurrence \& radionecrosis w/ mass effect } 4 \text { mos later; } \\
\text { died of progressive CNS disease } 3 \text { mos later }\end{array}$ \\
\hline 20 & 70 & 60 & 90 & 4 & 4 & 4 & Trauma & $\begin{array}{l}\text { Suffered fatal trauma w/ massive head injury; no evidence of CNS } \\
\text { mets }\end{array}$ \\
\hline 21 & 90 & 90 & 80 & 4 & 24 & 4 & S & Progression of systemic disease; no evidence of CNS disease \\
\hline 22 & 80 & 90 & 60 & 10 & 16 & 16 & $S$ & $\begin{array}{l}\text { New distant brain lesions } 10 \text { mos after I/B, none at op I/B site; all } \\
\text { treated w/ SRS; } 3 \text { mos later, multiple new brain lesions, none at op } \\
\text { I/B site, treated w/ WBRT ( } 37.5 \text { Gy/15 fractions); died of systemic } \\
\text { disease progression, w/ no evidence of active CNS disease }\end{array}$ \\
\hline
\end{tabular}


TABLE 2. Patient characteristics and outcomes* (continued)

\begin{tabular}{|c|c|c|c|c|c|c|c|c|}
\hline \multirow{2}{*}{$\begin{array}{l}\text { Patient } \\
\text { No. }\end{array}$} & \multicolumn{3}{|c|}{ KPS Score } & \multirow{2}{*}{$\begin{array}{l}\text { PFS } \\
\text { (mos) }\end{array}$} & \multirow{2}{*}{$\begin{array}{c}\text { OS } \\
(\mathrm{mos})\end{array}$} & \multirow{2}{*}{$\begin{array}{l}\text { CNS Survival } \\
\text { (mos) } \ddagger\end{array}$} & \multirow{2}{*}{$\begin{array}{l}\text { Cause of } \\
\text { Death }\end{array}$} & \multirow[b]{2}{*}{ Comments } \\
\hline & Preop & $1 \mathrm{Mo}^{*}$ & 3 Most & & & & & \\
\hline 23 & 70 & 70 & 90 & 5 & 13 & 5 & $S$ & $\begin{array}{l}\text { Died of systemic mets, unresponsive to chemo- or radiotherapy; no } \\
\text { evidence of CNS disease }\end{array}$ \\
\hline Mean & NA & NA & NA & 21.9 & 71.1 & 29.6 & & \\
\hline SD & NA & NA & NA & 32.8 & 63.5 & 31.5 & & \\
\hline Median & 80 & 90 & 90 & 9 & 36 & 18 & & \\
\hline Mode & 80 & 90 & 90 & & 35 & 10 & & \\
\hline
\end{tabular}

I/B = Intrabeam; IDL = isodose line; IMRT = intensity-modulated radiotherapy; OS = overall survival, from first diagnosis with the index cancer determined, at the time of microscopic examination of the BrM to be the source of the BrM (see Table 1); PFS = progression-free survival in the CNS, both at the site treated with tumor resection and Intrabeam, and/or elsewhere in the brain; Preop = on the morning of surgery; $\mathrm{S}=$ systemic.

* KPS score at the 1-month follow-up (or, after surgery, when stable, if less than 1 month).

+ KPS score at the 3-month follow-up.

$\ddagger$ CNS survival time from the initial diagnosis of BrM.

was stopped $13.1 \pm 3.3$ days (range 7-21 days) after surgery; administration and cessation were left to the discretion of the surgeon.

Postoperative progression-free survival, posttreatment survival, and overall survival times from the time of the first diagnosis of cancer according to RPA and GPA classifications are shown in Table 1. Median KPS scores before and 1 and 3 months after surgery are summarized in Table 2.

Seven patients had BrM recurrence at the site of treatment $9.0 \pm 5.7$ months after surgery+IORT. Five patients had new but distant BrM 16.6 \pm 2.8 months after treatment, and of 3 patients with histopathologically confirmed radiation necrosis, all of them had previous SRS, alone or in combination with WBRT to the index lesion (Table 2). Of the 7 patients with local disease recurrence, 3 had breast cancer, 2 had non-small cell lung cancer (NSCLCa), and 1 each had renal, endometrial, or bladder cancer (Table 2). Three of the 7 had pial penetration of tumor (which was resected) at the time of surgery, and each of these 3 (2 with breast cancer, 1 with NSCLCa) had leptomeningeal (metastatic) disease (LMD) as the form of local recurrence. Six patients later received WBRT, and 7 received radiosurgery; 2 patients receiving both treatments (Table 2).

Three patients remain alive with CNS progression-free survival of 90-96 months without additional treatment for their BrM. Nineteen patients died after a minimum of 5 years of follow-up: $11(58 \%)$ of systemic progression, $3(16 \%)$ of CNS progression, and $4(21 \%)$ of a combination of systemic and CNS progression; 1 patient (5\%) died when struck by a vehicle as a pedestrian. The complex medical and neurooncological treatment histories of all the patients, which were not controlled in this study, are representative of those of a busy neurooncology referral practice and are summarized in Table 2.

\section{Discussion}

Targeted IORT at the time of resection of a solitary BrM seems to be a safe and effective treatment. Data on survival and local recurrence in this study are shown in Table 2. Of the 7 patients with local recurrence, 3 had infiltration of the pia mater (which was resected with the specimen) at the time of surgery; however, all 3 of these patients devel- oped recurrence with LMD, suggesting that IORT may not be an optimal therapy for these patients. If one excludes these patients, only $4(20 \%)$ of the remaining 20 patients had local recurrence. Overall, performance statuses (KPS scores) and Folstein scores for assessing cognition did not show deterioration, suggesting that surgery combined with IORT that delivers a 14-Gy dose to the tumor margin is tolerated well in the CNS both locally and at a distance. Additional refinement of the dose for IORT was beyond the scope of this study. However, the moderately high local recurrence rates and lack of radiation necrosis in those who did not undergo further SRS suggest that a higher margin dose for the IORT may be useful and should be studied in future trials with this device.

These results compare favorably with the efficacies of current treatment options, including surgery, WBRT, and SRS, either alone or in various combinations. With surgery, the median survival of patients with solitary BrM treated with surgery alone is just over 10 months. $4,19,23,24,30-32,35,41,43$ Local and distant recurrence rates are $30.5 \%$ and $23.9 \%$, respectively. 4,19,23,24,30-32,41,43 With WBRT alone, the median survival of patients is approximately 4-7 months, and local and distant recurrence rates are $50 \%$ and $52 \%$, respectively.4,15,32,37,41 Local and distant recurrence rates seem similar, again at nearly $50 \% .^{4,15,32,37,41}$ These data are primarily historical, as modern advances in surgery and SRS have shifted WBRT from a common monotherapy ${ }^{4,11,30,32}$ to a modality more typically used as part of combination therapy. $4,24,32,35,40$ With SRS, the median survival in patients treated with SRS monotherapy for solitary BrM averages about 7 months or longer. ${ }^{20,32,41}$ Local and distant recurrence rates are approximately 30\%.,20,32,40,41 Surgery followed immediately by WBRT remains a common and effective strategy for managing a solitary BrM.4,15,19,31,32,41 The median survival of patients undergoing surgery plus WBRT is just over 10 months., ${ }^{4,15,19,24,31,32,35,41}$ Local and distant recurrence rates are approximately 10\%-30\% each after surgery combined with WBRT, depending on the study and frequency of follow-up. ${ }^{4,7,15,19,24,31,32,35,41}$ The rates of freedom from local and distant recurrence average approximately $80 \% .4,7,15,19,24,31,32,35,41$ Surgery followed by an SRS boost to the resection bed is a potential treatment option, but rigorous investigations of the efficacy of 
this strategy are presently unavailable in sufficient quantity to calculate reliable efficacy rates; however, most studies have reported rates similar to those of surgery plus WBRT, local recurrence rates of $6 \%-20 \%$, distant control rates of $35 \%-64 \%$, mean survival of 12-20 months, and the need for additional SRS or WBRT in $20 \%-40 \%$ of patients. ${ }^{6,17,20,25,26}$ Another frequently used combination therapy is SRS immediately followed by WBRT. The median survival of patients receiving combined therapy is 10-11 months, $4,20,26,32,37,40,41$ and local and distant recurrence rates range from $10 \%$ to $20 \%$. $4,20,26,32,37,40,41$

Targeted IORT has been used both for CNS lesions such as metastasis and for lesions outside the brain. Several authors have used interstitial iodine-125 brachytherapy seeds stereotactically implanted into metastatic tumors. ${ }^{3,27,33}$ In a study by Prados et al., ${ }^{33} 14$ patients had a median survival time of 63 weeks; however, reoperations for radionecrosis were common. Bernstein et al. ${ }^{3}$ treated 10 patients with recurrent disease; 5 patients died of recurrent disease 1 died of systemic disease, and there were 2 long-term survivors (3.5 and 6.2 years). Ostertag and $\mathrm{Kreth}^{27}$ treated 93 patients with brachytherapy by using a $60-$ Gy regimen; in 2 groups-one with primary and the other with recurrent metastases - the mean survival times were 15 and 6 months, respectively. Similar results were reported after BrM resection and intracavitary iodine- 125 brachytherapy were performed to treat 40 patients; the authors reported a median survival of 11.3 months, a recurrence rate of $12 \%$ at the cavity, a recurrence rate of $63 \%$ in the brain at 1 year, symptomatic radiation necrosis in $23 \%$, and local LMD in 5 patients. ${ }^{16}$ Two recent studies evaluated the use of IORT at the time of stereotactic biopsies in patients with BrMs. ${ }^{10,28}$ Curry et al. ${ }^{10}$ reported that of 60 patients with 72 lesions treated with a 16-Gy peripheral dose (range 10-20 Gy), those patients $(n=37)$ with a single treated lesion survived a mean of 11 months. Pantazis et al. ${ }^{28}$ reported on a series of 35 patients with a single metastasis treated with IORT after stereotactic biopsy and implantation of the IORT source; 32 of the patients received a dose of 18 Gy to the lesion wall, and 3 patients received a dose of 15 Gy. Most patients $(n=30)$ had treatment of a primary tumor; 5 had tumors that recurred after other therapy. The median survival after treatment was 7.4 months.

Thus, the results of our study and others suggest that IORT strategies, when delivered at the time of BrM resection, are feasible, generally safe, and effective, with results that are comparable to those of other treatments used commonly for patients with a BrM. The potential advantages of surgery combined with IORT include ease of use for physicians and convenience for patients because both therapies combined into a single session. ${ }^{26,42}$ There is also the potential for decreasing costs associated with separate therapies as well as the local nature of the treatment, thereby sparing distant areas of the brain that might not need to be treated with WBRT. Reserving WBRT for a later date potentially spares the remainder of the brain from a dose of radiation and may aid in preserving longterm neurocognition, an increasingly important aspect of the neurooncological care of patients with systemic cancer as newer therapies that increase systemic control and overall survival are developed. $5,21,29,45$
This study had limitations. This was a prospective, nonrandomized, single-institution study. More patients with a surgically accessible solitary BrM were seen than were treated with surgery. From this subgroup, more patients who were treated with surgery during this time period were either not eligible for or not interested in receiving IORT at the time of surgical resection. No patients with tumors located in the brainstem, midbrain, or deep cerebral nuclear structures or with tumors located infratentorially were in this study. We did not control for the treatment decisions of medical, radiation, or neurosurgical oncologists with respect to the treatment administered before entry to the study or for recurrent CNS or systemic disease, because many of the patients traveled to our center for only one or a few of their therapies, or the treating physicians or the patients themselves had different objectives with respect to risk, benefit, and desired outcome in those situations.

Patients with pial infiltration by tumor may be at greater risk of recurrence and may be less optimal candidates for surgery+IORT. In addition, 14 Gy to a 2-mm depth may not be optimal, although comparisons with the results of Curry et al..$^{10}$ (mean 16 Gy, local control rate $81 \%$ ) and Pantazis et al..$^{28}$ (15 or $18 \mathrm{~Gy}$, with local control rates < $50 \%$ at 1 year) suggest that our local and distant control rates are comparable to those of other studies and other treatment methods such as surgery alone, surgery plus WBRT, or SRS alone, while having enhanced, on average, rates of progression-free, posttreatment, and overall survival. Furthermore, the treated lesions had diverse origins, differing natural histories, and different presentations. However, the patients treated represent the typical panoply of metastatic disease seen in most neurooncological referral centers, and so this study recapitulates the treatment decisions confronted.

\section{Conclusions}

This study demonstrates the general safety, feasibility, and potential utility of resection, combined with IORT at a dose of 14 Gy to a 2-mm peripheral margin to treat patients with a solitary BrM. The rates of local control, distant control, and long-term survival are at least comparable to those associated with other commonly used modalities. Surgery plus IORT seems to be a potential complement or adjunct to the multimodality treatment of patients with systemic cancer with CNS involvement and may warrant further study, including the evaluation of increasing the dose delivered with IORT.

\section{References}

1. Astor MB, Hilaris BS, Gruerio A, Varricchione T, Smith D: Preclinical studies with the photon radiosurgery system (PRS). Int J Radiat Oncol Biol Phys 47:809-813, 2000

2. Barker FG II: Craniotomy for the resection of metastatic brain tumors in the U.S., 1988-2000: decreasing mortality and the effect of provider caseload. Cancer 100:999-1007, 2004

3. Bernstein M, Cabantog A, Laperriere N, Leung P, Thomason C: Brachytherapy for recurrent single brain metastasis. Can J Neurol Sci 22:13-16, 1995

4. Brem SS, Bierman PJ, Brem H, Butowski N, Chamberlain 
MC, Chiocca EA, et al: Central nervous system cancers. J Natl Compr Canc Netw 9:352-400, 2011

5. Chang EL, Wefel JS, Hess KR, Allen PK, Lang FF, Kornguth DG, et al: Neurocognition in patients with brain metastases treated with radiosurgery or radiosurgery plus whole-brain irradiation: a randomised controlled trial. Lancet Oncol 10:1037-1044, 2009

6. Choi CYH, Chang SD, Gibbs IC, Adler JR, Harsh GR IV, Lieberson RE, et al: Stereotactic radiosurgery of the postoperative resection cavity for brain metastases: prospective evaluation of target margin on tumor control. Int J Radiat Oncol Biol Phys 84:336-342, 2012

7. Clarke JW, Register S, McGregor JM, Grecula JC, Mayr NA, Wang JZ, et al: Stereotactic radiosurgery with or without whole brain radiotherapy for patients with a single radioresistant brain metastasis. Am J Clin Oncol 33:70-74, 2010

8. Colombo F, Francescon P, Cavedon C, Casentini L, Zanusso $\mathrm{M}$ : Employ of a new device for intra-operative radiotherapy of intracranial tumours. Acta Neurochir (Wien) 143:827831,2001

9. Crum RM, Anthony JC, Bassett SS, Folstein MF: Populationbased norms for the Mini-Mental State Examination by age and educational level. JAMA 269:2386-2391, 1993

10. Curry WT Jr, Cosgrove GR, Hochberg FH, Loeffler J, Zervas NT: Stereotactic interstitial radiosurgery for cerebral metastases. J Neurosurg 103:630-635, 2005

11. Douglas RM, Beatty J, Gall K, Valenzuela RF, Biggs P, Okunieff P, et al: Dosimetric results from a feasibility study of a novel radiosurgical source for irradiation of intracranial metastases. Int J Radiat Oncol Biol Phys 36:443-450, 1996

12. Drappatz J, Wen PY: Chemotherapy and targeted molecular therapies for brain metastases. Expert Rev Neurother 6:1465-1479, 2006

13. Eichler AF, Chung E, Kodack DP, Loeffler JS, Fukumura D, Jain RK: The biology of brain metastases-translation to new therapies. Nat Rev Clin Oncol 8:344-356, 2011

14. Gallina P, Francescon P, Cavedon C, Casamassima F, Mungai $\mathrm{R}$, Perrini P, et al: Stereotactic interstitial radiosurgery with a miniature $\mathrm{X}$-ray device in the minimally invasive treatment of selected tumors in the thalamus and the basal ganglia. Stereotact Funct Neurosurg 79:202-213, 2002

15. Gaspar LE, Mehta MP, Patchell RA, Burri SH, Robinson PD, Morris RE, et al: The role of whole brain radiation therapy in the management of newly diagnosed brain metastases: a systematic review and evidence-based clinical practice guideline. J Neurooncol 96:17-32, 2010

16. Huang K, Sneed PK, Kunwar S, Kragten A, Larson DA, Berger MS, et al: Surgical resection and permanent iodine-125 brachytherapy for brain metastases. J Neurooncol 91:83-93, 2009

17. Jensen CA, Chan MD, McCoy TP, Bourland JD, deGuzman $\mathrm{AF}$, Ellis TL, et al: Cavity-directed radiosurgery as adjuvant therapy after resection of a brain metastasis. J Neurosurg 114:1585-1591, 2011

18. Kalapurakal JA, Goldman S, Stellpflug W, Curran J, Sathiaseelan V, Marymont MH, et al: Phase I study of intraoperative radiotherapy with photon radiosurgery system in children with recurrent brain tumors: preliminary report of first dose level (10 Gy). Int J Radiat Oncol Biol Phys 65:800-808, 2006

19. Kalkanis SN, Kondziolka D, Gaspar LE, Burri SH, Asher AL, Cobbs CS, et al: The role of surgical resection in the management of newly diagnosed brain metastases: a systematic review and evidence-based clinical practice guideline. J Neurooncol 96:33-43, 2010

20. Linskey ME, Andrews DW, Asher AL, Burri SH, Kondziolka $\mathrm{D}$, Robinson PD, et al: The role of stereotactic radiosurgery in the management of patients with newly diagnosed brain metastases: a systematic review and evidence-based clinical practice guideline. J Neurooncol 96:45-68, 2010
21. Marko NF, Weil RJ: Radiotherapy: Neurocognitive considerations in the treatment of brain metastases. Nat Rev Clin Oncol 7:185-186, 2010

22. Mehta MP, Paleologos NA, Mikkelsen T, Robinson PD, Ammirati M, Andrews DW, et al: The role of chemotherapy in the management of newly diagnosed brain metastases: a systematic review and evidence-based clinical practice guideline. J Neurooncol 96:71-83, 2010

23. Mintz AH, Kestle J, Rathbone MP, Gaspar L, Hugenholtz H, Fisher B, et al: A randomized trial to assess the efficacy of surgery in addition to radiotherapy in patients with a single cerebral metastasis. Cancer 78:1470-1476, 1996

24. Muacevic A, Kreth FW, Horstmann GA, Schmid-Elsaesser R, Wowra B, Steiger HJ, et al: Surgery and radiotherapy compared with gamma knife radiosurgery in the treatment of solitary cerebral metastases of small diameter. J Neurosurg 91:35-43, 1999

25. Ogiwara H, Kalakota K, Rakhra SS, Helenowski IB, Marymont MH, Kalapurakal JA, et al: Intracranial relapse rates and patterns, and survival trends following post-resection cavity radiosurgery for patients with single intracranial metastases. J Neurooncol 108:141-146, 2012

26. Olson JJ, Paleologos NA, Gaspar LE, Robinson PD, Morris $\mathrm{RE}$, Ammirati M, et al: The role of emerging and investigational therapies for metastatic brain tumors: a systematic review and evidence-based clinical practice guideline of selected topics. J Neurooncol 96:115-142, 2010

27. Ostertag CB, Kreth FW: Interstitial iodine- 125 radiosurgery for cerebral metastases. Br J Neurosurg 9:593-603, 1995

28. Pantazis G, Trippel M, Birg W, Ostertag CB, Nikkhah G: Stereotactic interstitial radiosurgery with the Photon Radiosurgery System (PRS) for metastatic brain tumors: a prospective single-center clinical trial. Int J Radiat Oncol Biol Phys 75:1392-1400, 2009

29. Park CC, Yom SS, Podgorsak MB, Harris E, Price RA Jr, Bevan A, et al: American Society for Therapeutic Radiology and Oncology (ASTRO) emerging technology committee report on electronic brachytherapy. Int J Radiat Oncol Biol Phys 76:963-972, 2010

30. Patchell RA, Tibbs PA, Regine WF, Dempsey RJ, Mohiuddin M, Kryscio RJ, et al: Postoperative radiotherapy in the treatment of single metastases to the brain: a randomized trial. JAMA 280:1485-1489, 1998

31. Patchell RA, Tibbs PA, Walsh JW, Dempsey RJ, Maruyama Y, Kryscio RJ, et al: A randomized trial of surgery in the treatment of single metastases to the brain. N Engl J Med 322:494-500, 1990

32. Patil CG, Pricola K, Sarmiento JM, Garg SK, Bryant A, Black KL: Whole brain radiation therapy (WBRT) alone versus WBRT and radiosurgery for the treatment of brain metastases. Cochrane Database Syst Rev 9:CD006121, 2012

33. Prados M, Leibel S, Barnett CM, Gutin P: Interstitial brachytherapy for metastatic brain tumors. Cancer 63:657-660, 1989

34. Rogers LR, Rock JP, Sills AK, Vogelbaum MA, Suh JH, Ellis TL, et al: Results of a phase II trial of the GliaSite radiation therapy system for the treatment of newly diagnosed, resected single brain metastases. J Neurosurg 105:375-384, 2006

35. Roos DE, Smith JG, Stephens SW: Radiosurgery versus surgery, both with adjuvant whole brain radiotherapy, for solitary brain metastases: a randomised controlled trial. Clin Oncol (R Coll Radiol) 23:646-651, 2011

36. Schag CC, Heinrich RL, Ganz PA: Karnofsky performance status revisited: reliability, validity, and guidelines. J Clin Oncol 2:187-193, 1984

37. Scoccianti S, Ricardi U: Treatment of brain metastases: review of phase III randomized controlled trials. Radiother Oncol 102:168-179, 2012

38. Soffietti R, Cornu P, Delattre JY, Grant R, Graus F, Grisold 
W, et al: EFNS Guidelines on diagnosis and treatment of brain metastases: report of an EFNS Task Force. Eur J Neurol 13:674-681, 2006

39. Sperduto PW, Kased N, Roberge D, Xu Z, Shanley R, Luo X, et al: Summary report on the graded prognostic assessment: an accurate and facile diagnosis-specific tool to estimate survival for patients with brain metastases. J Clin Oncol 30:419-425, 2012

40. Suh JH: Stereotactic radiosurgery for the management of brain metastases. N Engl J Med 362:1119-1127, 2010

41. Suh JH, Videtic GM, Aref AM, Germano I, Goldsmith BJ, Imperato JP, et al: ACR Appropriateness Criteria: single brain metastasis. Curr Probl Cancer 34:162-174, 2010

42. Vaidya JS, Joseph DJ, Tobias JS, Bulsara M, Wenz F, Saunders C, et al: Targeted intraoperative radiotherapy versus whole breast radiotherapy for breast cancer (TARGIT-A trial): an international, prospective, randomised, non-inferiority phase 3 trial. Lancet 376:91-102, 2010

43. Vecht CJ, Haaxma-Reiche H, Noordijk EM, Padberg GW, Voormolen JH, Hoekstra FH, et al: Treatment of single brain metastasis: radiotherapy alone or combined with neurosurgery? Ann Neurol 33:583-590, 1993

44. Vogelbaum MA, Asher AL, Kondziolka D, Boulis NM, Selden NR, Hoh BL, et al: Modern treatment of cerebral metastases: Integrated Medical Learning ${ }^{\text {SM }}$ at CNS 2007. J Neurooncol 93:89-105, 2009
45. Wong J, Hird A, Kirou-Mauro A, Napolskikh J, Chow E: Quality of life in brain metastases radiation trials: a literature review. Curr Oncol 15:25-45, 2008

46. Wong J, Hird A, Zhang L, Tsao M, Sinclair E, Barnes E, et al: Symptoms and quality of life in cancer patients with brain metastases following palliative radiotherapy. Int J Radiat Oncol Biol Phys 75:1125-1131, 2009

\section{Author Contributions}

Conception and design: Toms, Weil, Chao. Acquisition of data: Weil, Mavinkurve, Chao, Vogelbaum, Suh, Kolar. Analysis and interpretation of data: Toms, Weil, Mavinkurve, Vogelbaum, Suh. Drafting the article: all authors. Critically revising the article: all authors. Reviewed submitted version of manuscript: all authors. Approved the final version of the manuscript on behalf of all authors: Toms. Statistical analysis: Toms, Weil, Mavinkurve.

\section{Correspondence}

Steven A. Toms, Department of Neurosurgery, MC 14-05, Geisinger Health System, 100 North Academy Ave., Danville, PA 17822.email: satoms@geisinger.edu. 